\title{
High Reversibility of "Soft" Electrode Materials in All-Solid-State Batteries
}

\author{
Atsushi Sakuda*, Tomonari Takeuchi*, Masahiro Shikano, Hikari Sakaebe and \\ Hironori Kobayashi
}

Department of Energy and Environment, Research Institute for Electrochemical Energy, National Institute of Advanced Industrial Science and Technology (AIST), Ikeda, Japan

All-solid-state batteries using inorganic solid electrolytes (SEs) are considered to be ideal batteries for electric vehicles and plug-in hybrid electric vehicles because they are potentially safer than conventional lithium-ion batteries (LIBs). In addition, all-solid-state batteries are expected to have long battery life owing to the inhibition of chemical side reactions because only lithium ions move through the typically used inorganic SEs. The development of high-energy density (more than $300 \mathrm{Wh} \mathrm{kg}^{-1}$ ) secondary batteries has been eagerly anticipated for years. The application of high-capacity electrode active materials is essential for fabricating such batteries. Recently, we proposed metal polysulfides as new electrode materials. These materials show higher conductivity and density than sulfur, which is advantageous for fabricating batteries with relatively higher energy density. Lithium niobium sulfides, such as $\mathrm{Li}_{3} \mathrm{NbS}_{4}$, have relatively high density, conductivity, and rate capability among metal polysulfide materials, and batteries with these materials have capacities high enough to potentially exceed the gravimetric-energy density of conventional LIBs. Favorable solid-solid contact between the electrode and electrolyte particles is a key factor for fabricating high performance all-solid-state batteries. Conventional oxide-based positive electrode materials tend to give rise to cracks during fabrication and/or charge-discharge processes. Here, we report all-solid-state cells using lithium niobium sulfide as a positive electrode material, where favorable solid-solid contact was established by using lithium sulfide electrode materials because of their high processability. Cracks were barely observed in the electrode particles in the all-solid-state cells before or after charging and discharging with a high capacity of approximately $400 \mathrm{mAh} \mathrm{g}^{-1}$ suggesting that the lithium niobium sulfide electrode charged and discharged without experiencing substantial mechanical damage. As a result, the all-solid-state cells retained more than $90 \%$ of their initial capacity after 200 cycles of charging and discharging at $0.5 \mathrm{~mA} \mathrm{~cm}^{-2}$.

Keywords: all-solid-state battery, lithium niobium sulfide, electrode morphology, sulfide solid electrolyte, long cycle life

\section{INTRODUCTION}

Secondary batteries are one of the most important components of electric vehicles (EVs) and plug-in hybrid electric vehicles (PHEVs). Among many types of secondary batteries, lithium-ion batteries (LIBs) are typically used in current EVs and PHEVs because of their high-energy density and long life (Armand and Tarascon, 2008; Dunn et al., 2011; Etacheri et al., 2011). To achieve a long driving range, the batteries must be densely packed in the battery pack because of the limited space for 
batteries in EVs and PHEVs. However, this dense packing usually increases the operating temperature of batteries. Thus, the safety and cyclability of these batteries at high temperature must be improved for use in EVs and PHEVs; otherwise, large-volume cooling units will be required.

Conventional LIBs employ liquid electrolytes with organic solvents (Armand and Tarascon, 2008; Dunn et al., 2011). These batteries are associated with some safety risks and exhibit accelerated degradation when they are operated at high temperatures. All-solid-state batteries that use inorganic solid electrolytes (SEs) are considered to be ideal batteries for EVs and PHEVs because they are potentially safer than conventional LIBs (Minami et al., 2006; Kamaya et al., 2011; Sakuda et al., 2013a). In addition, these batteries are expected to have long battery life because of the inhibition of chemical side reactions as only the lithium ions move in the typically used inorganic SEs.

The development of high-energy density (more than $300 \mathrm{Wh} \mathrm{kg}^{-1}$ ) secondary batteries has been eagerly anticipated for years. The application of high-capacity electrode-active materials is essential for the fabrication of such batteries. Lithium/sulfur batteries have attracted attention because of their high theoretical energy densities based on the high capacities of sulfur in positive electrode materials (Yamin and Peled, 1983; Ji et al., 2009; Bruce et al., 2012; Schuster et al., 2012). However, the use of sulfurcarbon composites is required to activate insulating sulfur, and the composites require large amounts of carbon to achieve high performance, which decreases their energy density. Recently, we proposed metal polysulfides as new electrode materials (Hayashi et al., 2012a; Matsuyama et al., 2012; Sakuda et al., 2013b, 2014a,b,c,d). These materials show higher conductivity and density than sulfur. Thus, they are expected to exhibit improved volumetric-energy densities because of their relatively low conductive carbon ratios and relatively high material densities.

Understanding and exploiting the materials' mechanical properties are important in all-solid-state batteries (Hayashi et al., 2012b; Sakuda et al., 2013a). The all-solid-state batteries with sulfide SEs can be fabricated through high-pressure pressing at room temperature because of the sulfide SEs unique mechanical properties. The sulfide SE powder becomes highly densified as the grain boundaries decrease during pressing at room temperature. We term this densification "room-temperature pressure sintering" (Sakuda et al., 2013a). This phenomenon enables the creation of intimate contact between the electrode and SE materials, which is an essential requirement for all-solid-state operation, via room-temperature processing. The mechanical properties of electrode materials are also important. When brittle materials are used as the active material, the fragmentation of the electrode particles may occur during the high-pressure pressing used for cell construction. This fragmentation is especially serious at the interfaces between brittle materials as a result of stress concentration during high-pressure pressing (Sakuda et al., 2016). When electrode materials with some plastic character are used, the morphology of the electrode layer differs from that when brittle materials are used. For instance, the fragmentation during highpressure pressing is expected to be suppressed. Furthermore, a dense electrode layer with a favorable electrode-electrolyte interface can likely be constructed. Electrode materials with large capacities usually show large volume changes during charging and discharging. The maintenance of intimate solid-solid contact is an essential requirement for long cycle life. The plasticity of the electrode materials is believed to affect the maintenance of this contact. Lithium-containing metal sulfides with threedimensional (3D) structures are attractive model materials with some degree of plastic character based on an intermediate bond character between ionic and covalent. Lithium niobium sulfides, such as rock-salt $\mathrm{Li}_{3} \mathrm{NbS}_{4}$, have relatively high density, conductivity, and rate capability among metal polysulfide materials (Sakuda et al., 2014c,d). Additionally, the batteries that use these materials have capacities that are high enough to potentially exceed the gravimetric-energy density of conventional LIBs. Furthermore, $\mathrm{Li}_{3} \mathrm{NbS}_{4}$ is considered to have relatively soft mechanical nature. Its application in all-solid-state batteries is expected to enhance these batteries' cyclability.

Here, we report high reversibility of soft electrode materials in all-solid-state batteries. The $\mathrm{Li}_{3} \mathrm{NbS}_{4}$ is used as a model material of soft electrode materials. This material shows unique mechanical properties that it can be densified by pressing at room temperature, and charged and discharged without the fragmentation. As a result, a dense electrode layer with a favorable conducting pathway and electrode-electrolyte interface is constructed. Furthermore, the dense electrode layer is maintained during charging and discharging, and the all-solid-state cell created here has a long cycle performance.

\section{MATERIALS AND METHODS}

$\mathrm{Li}_{3} \mathrm{NbS}_{4}$ was mechanochemically synthesized using a planetary ball mill apparatus (P-5, Fritsch $\mathrm{GmbH}$ ). In an argon-filled glove box, a mixture of lithium sulfide $\left(\mathrm{Li}_{2} \mathrm{~S}, 99.9 \%\right.$, Mitsuwa Pure Chemicals), niobium disulfide $\left(\mathrm{NbS}_{2}, 99 \%\right.$, High Purity Chemicals), and sulfur $\left(\mathrm{S}_{8}, 99.9 \%\right.$, Wako Pure Chemical Industries) was placed into a zirconia pot $(500 \mathrm{~mL})$ along with zirconia balls ( $4 \mathrm{~mm}$ in diameter, 1,000 g). The total weight of the mixture of the starting materials was $10 \mathrm{~g}$. The rotation speed and time of ball milling were fixed at $250 \mathrm{rpm}$ and $120 \mathrm{~h}(60 \mathrm{~min} \times 120$ times), respectively. The $75 \mathrm{Li}_{2} \mathrm{~S} \cdot 25 \mathrm{P}_{2} \mathrm{~S}_{5}$ (mol\%) glassy SE (Hayashi et al., 2001) was used, because it is the most typical sulfide-based $\mathrm{SE}$. The SE was mechanochemically prepared from $\mathrm{Li}_{2} \mathrm{~S}$ and phosphorus pentasulfide $\left(\mathrm{P}_{2} \mathrm{~S}_{5}, 99 \%\right.$, Sigma-Aldrich) via planetary ball milling. Heptane was used as the ball-milling solvent. Zirconia pots $(500 \mathrm{~mL})$ and zirconia balls $(4 \mathrm{~mm}$ in diameter, $1,000 \mathrm{~g}$ ) were used. The starting materials were weighed in an argon-filled glove box and milled in air-sealing pots for $20 \mathrm{~h}$. The lithium-ion conductivity of the powder-compressed pellet of the as-prepared SE and smaller-sized SE particles exhibited almost the same value (approximately $4 \times 10^{-4} \mathrm{~S} \mathrm{~cm}^{-1}$ ) at $25^{\circ} \mathrm{C}$. All-solid-state cells were constructed as follows. The $\mathrm{Li}_{3} \mathrm{NbS}_{4}$ and the SE were mixed at a weight ratio of 75:25 for 3 min using a vortex mixer $\left(\mathrm{IKA}^{\circledR}\right.$ Lab Dancer test tube shakers) via a dry process to prepare the positive composite electrode. The conductive additive was not included in this study because electronic conductivity of the $\mathrm{Li}_{3} \mathrm{NbS}_{4}$ is sufficiently high $\left(>2 \times 10^{-3} \mathrm{~S} \mathrm{~cm}^{-1}\right)$ relative to the lithium-ion conductivity in the composite electrode (Sakuda et al., 2014c,d). The resistance component attributable 
to electronic resistance in the composite electrode was hardly observed by AC impedance measurements. A lithium-indium alloy was used as the counter/reference electrode for the twoelectrode cell. The lithium-indium alloy has been reported to show a voltage plateau at $0.62 \mathrm{~V}$ vs. $\mathrm{Li}^{+} / \mathrm{Li}$, over a wide range of compositions (Takada et al., 1996). Bilayer pellets $(\varphi=10 \mathrm{~mm})$ consisting of the positive composite electrodes $(10 \mathrm{mg})$ and the SE (80 mg) were obtained by pressing under $330 \mathrm{MPa}$ at room temperature; indium foil $(t=0.3 \mathrm{~mm}, \varphi=9 \mathrm{~mm})$ and lithium foil ( $t=0.2 \mathrm{~mm}, \varphi=8 \mathrm{~mm}$ ) were then attached to the bilayer pellets by pressing under $100 \mathrm{MPa}$. The pellets were pressed using two stainless steel rods, which were used as current collectors for both the positive and negative electrodes. All the processes involved in preparing the all-solid-state cells were performed in an argon-filled glove box $\left[\left(\mathrm{H}_{2} \mathrm{O}\right)<1 \mathrm{ppm}\right]$.

Powder XRD measurements were performed at room temperature over the $2 \theta$ angle range $10^{\circ} \leq 2 \theta \leq 80^{\circ}$ with a step size of $0.1^{\circ}$ using a D8 ADVANCE (Bruker AXS) diffractometer with $\mathrm{CuK} \alpha$ radiation. The particle size distribution was measured using a particle size analyzer (SALD-7500nano, Shimadzu) with heptane/dibutyl ether as a solvent. Cross sections of the all-solid-state cells were prepared for scanning electron microscopy (SEM) observation using an argon-ion beam cross-section polisher (CP; IB-9020CP, JEOL) with an air-sealing holder. The samples were placed in the argon-filled glove box, transferred to the CP using the air-sealing holder, and milled for approximately $2 \mathrm{~h}$. The acceleration voltage and argon gas pressure used were $6 \mathrm{kV}$ and $3 \times 10^{-3} \mathrm{~Pa}$, respectively. During argon-ion milling, the stage was rocked $\pm 30^{\circ}$ to prevent beam striations and ensure uniform etching of the composite materials. Then, the obtained cross-section samples were transferred to the glove box and placed in the transfer vessel for SEM (JSM-6510A, JEOL) observation. The charge-discharge performances were evaluated at $50^{\circ} \mathrm{C}$.

\section{RESULTS}

Figure 1 shows the XRD patterns of the $\mathrm{Li}_{3} \mathrm{NbS}_{4}$ prepared by mechanical milling (MM) with some reference materials. The peaks attributable to rock-salt type $\mathrm{Li}_{3} \mathrm{NbS}_{4}$ (Sakuda et al., 2014c,d) were confirmed after MM for $120 \mathrm{~h}$, according to the preparation conditions used in this study. The average crystalline diameter of the $\mathrm{Li}_{3} \mathrm{NbS}_{4}$ estimated from the XRD peak widths was $<10 \mathrm{~nm}$, indicating that the sample obtained here included an amorphous phase.

Figure 2 shows the SEM images of the (Figure $2 \mathrm{~A}$ ) $\mathrm{Li}_{3} \mathrm{NbS}_{4}$ and (Figure 2B) $75 \mathrm{Li}_{2} \mathrm{~S} \cdot 25 \mathrm{P}_{2} \mathrm{~S}_{5}$ glassy $\mathrm{SE}$ particles. The average particle sizes of the $\mathrm{Li}_{3} \mathrm{NbS}_{4}$ and $75 \mathrm{Li}_{2} \mathrm{~S} \cdot 25 \mathrm{P}_{2} \mathrm{~S}_{5}$ glassy particles measured by the particle size analyzer were 5.7 and $15 \mu \mathrm{m}$, respectively. The $\mathrm{Li}_{3} \mathrm{NbS}_{4}$ particles are smaller than the SE particles in this study.

Figure 3 shows the cross-sectional SEM image of the positive electrode layer. The light- and dark-gray particles are $\mathrm{Li}_{3} \mathrm{NbS}_{4}$ and the SE, respectively. The dense pellet was obtained by pressing at room temperature. It should be noted that the grain boundaries are hardly visible at some interfaces between $\mathrm{Li}_{3} \mathrm{NbS}_{4}$ particles. No cracking or fragmentation can be seen in the $\mathrm{Li}_{3} \mathrm{NbS}_{4}$.

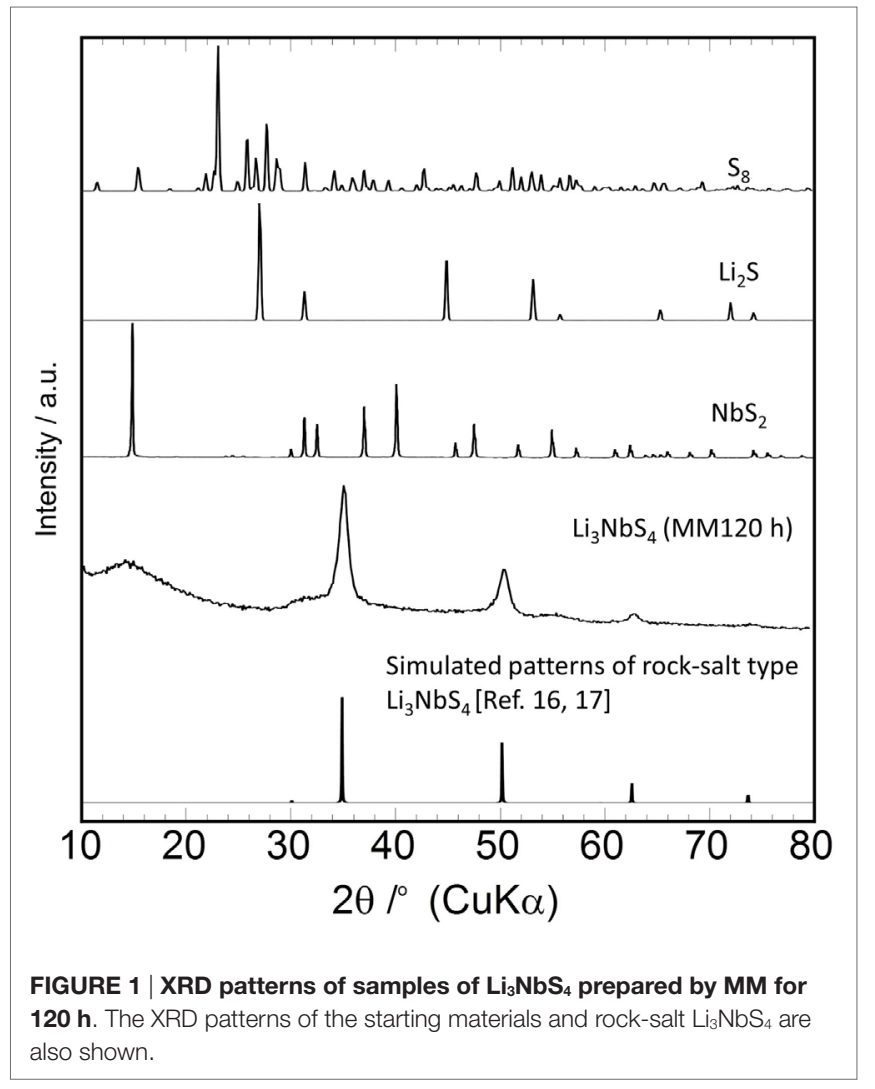

Figure 4 shows the dependence of the density of the $\mathrm{Li}_{3} \mathrm{NbS}_{4}$ pellet on the molding pressure. In this measurement, the $\mathrm{Li}_{3} \mathrm{NbS}_{4}$ was uniaxially compressed in a $10-\mathrm{mm}$-diameter mold. The relative densities were defined by the ratios between the pellets' densities and the powder true density, which was determined using a gas pycnometer (AccuPyc II 1340, Shimadzu), and the relative density was $2.92 \mathrm{~g} \mathrm{~cm}^{-3}$ for $\mathrm{Li}_{3} \mathrm{NbS}_{4}$. The relative density increases as the applied pressure increases and exceeds $90 \%$ when the $\mathrm{Li}_{3} \mathrm{NbS}_{4}$ powder is compressed by a pressure of over $500 \mathrm{MPa}$. Compressed $\mathrm{Li}_{3} \mathrm{NbS}_{4}$ with a remarkably high relative density can be obtained by pressing without heat treatment. Thus, $\mathrm{Li}_{3} \mathrm{NbS}_{4}$ is amenable to room-temperature pressure sintering.

Figure 5A shows the charge-discharge curves of the allsolid-state $\mathrm{Li}-\mathrm{In} / \mathrm{Li}_{3} \mathrm{NbS}_{4}$ cells. The current density used was $0.25 \mathrm{~mA} \mathrm{~cm}^{-2}$. Cutoff voltages of 2.4 and $0.9 \mathrm{~V}$ (vs. Li-In) were used in this study and correspond to 3.0 and $1.5 \mathrm{~V}$ (vs. $\mathrm{Li}^{+} / \mathrm{Li}$ ). Figure 5B presents the charge-discharge curves, with the number of lithium atoms per formula unit shown on the $x$-axis. The initial charge and discharge capacities were 263 and $370 \mathrm{mAh} \mathrm{g}^{-1}$, respectively. After the first cycle, a capacity of $c a .370 \mathrm{mAh} \mathrm{g}^{-1}$ was maintained for the charge and discharge process; however, a small increase in the capacity believed to be attributable to some sort of electrode activation was observed. This capacity corresponds to structures ranging from $\mathrm{Li}_{0.6} \mathrm{NbS}_{4}$ to $\mathrm{Li}_{4.0} \mathrm{NbS}_{4}$. The reversible capacity per unit area was $3.54 \mathrm{mAh} \mathrm{cm}^{-2}$. Rock-salt $\mathrm{Li}_{3} \mathrm{NbS}_{4}$ has been reported to exhibit reversible charging and discharging for compositions ranging between $\mathrm{Li}_{0.4} \mathrm{NbS}_{4}$ and $\mathrm{Li}_{3.9} \mathrm{NbS}_{4}$ when charged and discharged with cutoff voltages of 3.0 and $1.5 \mathrm{~V}$ 


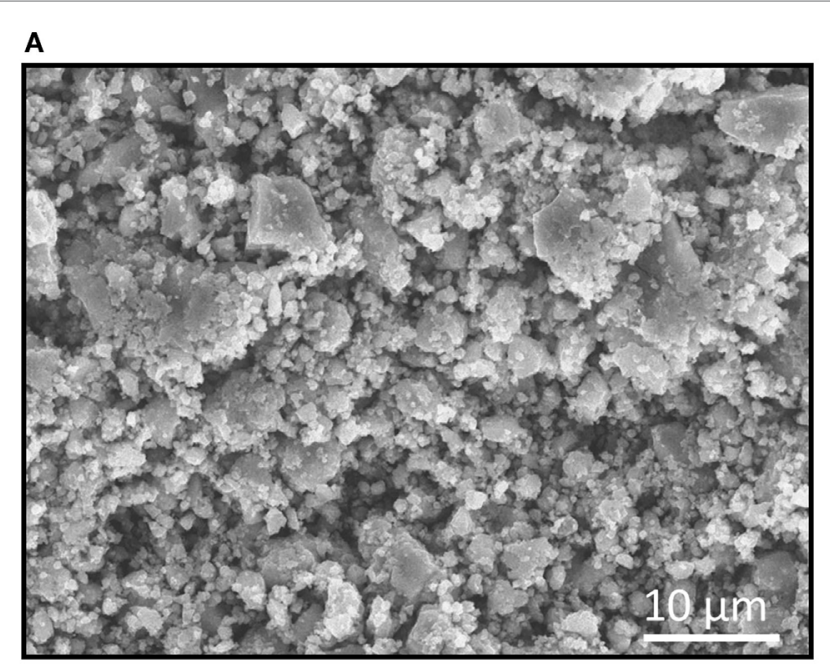

B

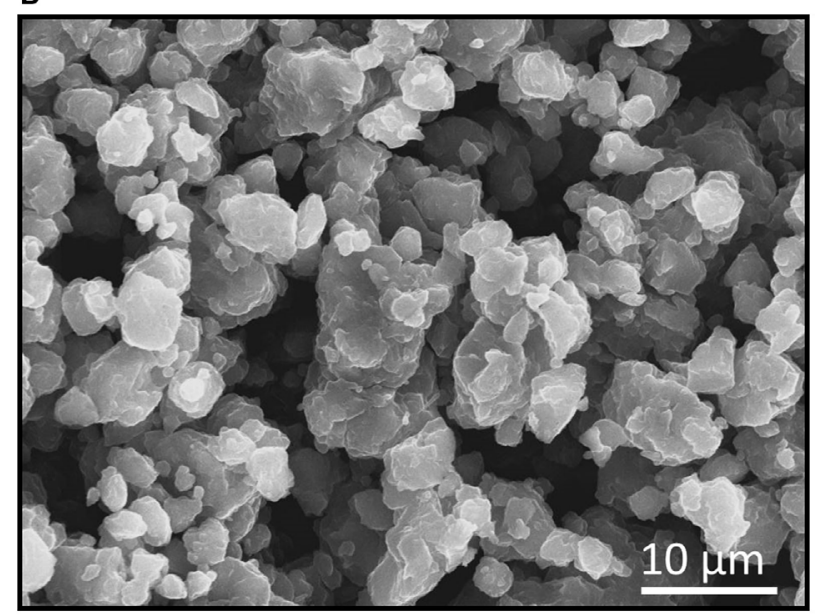

FIGURE 2 | SEM images of (A) $\mathrm{Li}_{3} \mathrm{NbS}_{4}$ prepared by MM for $120 \mathrm{~h}$ and (B) $75 \mathrm{Li}_{2} \mathrm{~S} \cdot 25 \mathrm{P}_{2} \mathrm{~S}_{5}$ glassy SE particles.

(vs. $\mathrm{Li}^{+} / \mathrm{Li}$ ), respectively (Sakuda et al., 2014c). Thus, $\mathrm{Li}_{3} \mathrm{NbS}_{4}$ can be used in all-solid-state cells as well as in the cells with carbonate-based liquid electrolytes. The potentials for charging and discharging were almost the same as those in cells with carbonate-based liquid electrolytes.

Figure 6 shows the cross-sectional SEM image of the positive composite electrode layer after the first charging (Figure 6A) and discharging (Figure 6B). The respective EDX mappings for $\mathrm{Nb}, \mathrm{P}$, and $\mathrm{S}$ are also shown in Figures 6C,D. The figures show that the electrode layers are free of cracks. The EDX mappings show that the light- and dark-gray particles are $\mathrm{Li}_{3} \mathrm{NbS}_{4}$ and the $\mathrm{SE}$, respectively. The void volume increases after charging, and it decreases after discharging. It is noted that the $\mathrm{Li}_{3} \mathrm{NbS}_{4}$ particles are well connected in the composite electrode after discharging process. The fragmentation of $\mathrm{Li}_{3} \mathrm{NbS}_{4}$ is hardly observed.

Figure 7 shows the cycle performance of the all-solid-state cell. The current densities used for the cycle test were $0.25 \mathrm{~mA} \mathrm{~cm}^{-2}$ for the first through fifth cycles and $0.5 \mathrm{~mA} \mathrm{~cm}^{-2}$ after the sixth cycle. The capacity decreased only slightly when the current

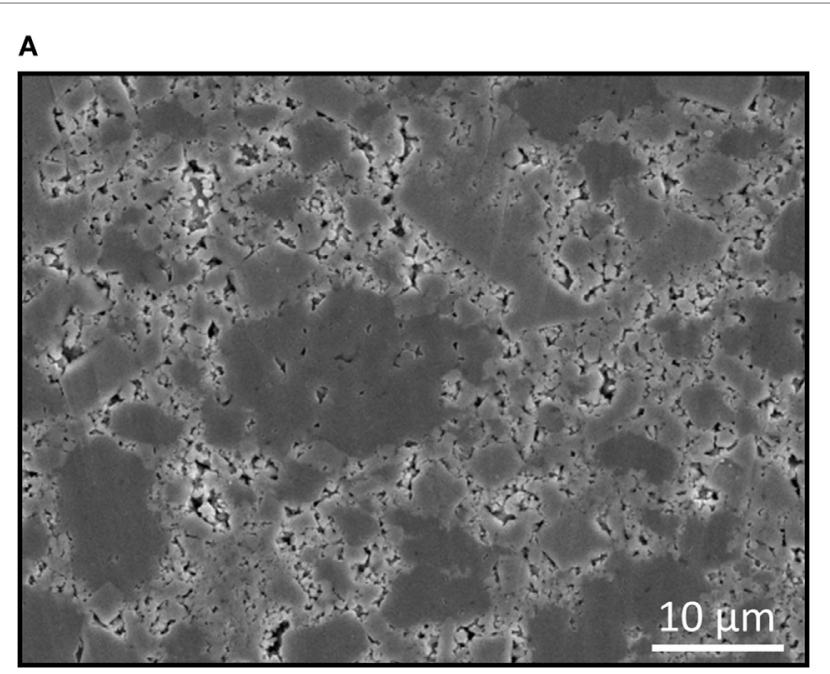

B

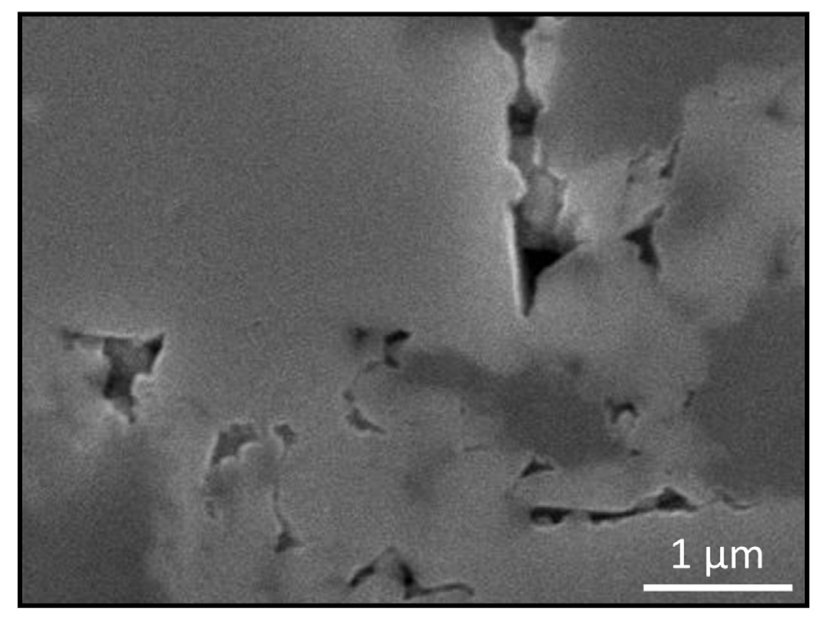

FIGURE 3 | Cross-sectional SEM images of the composite electrode of the all-solid-state cell with $\mathrm{Li}_{3} \mathrm{NbS}_{4}$. (A) Low- and (B) highmagnification images.

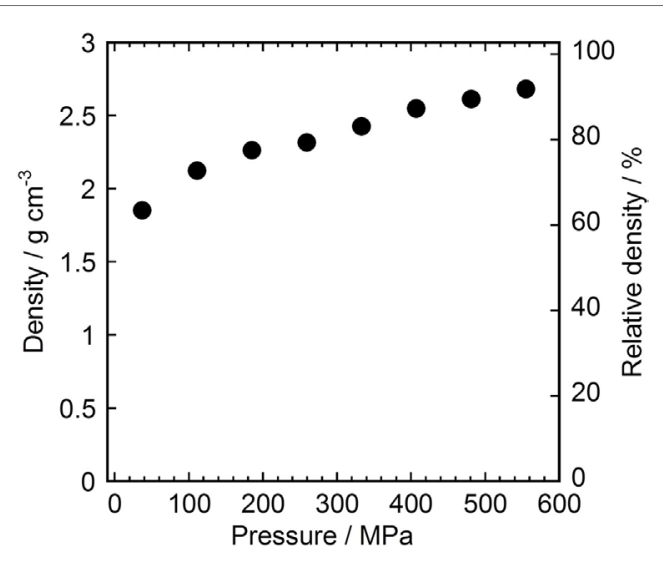

FIGURE 4 | Molding pressure dependence of the relative density of $\mathrm{Li}_{3} \mathrm{NbS}_{4}$. 
density changed from 0.25 to $0.5 \mathrm{~mA} \mathrm{~cm}{ }^{-2}$. The all-solid-state cell exhibited high cyclability, retaining $92.3 \%$ of its capacity from the 7 th to 200 th cycle. The average cycle efficiency was $99.96 \%$ per cycle, and the average coulombic efficiency was $99.998 \%$.

\section{DISCUSSION}

The experimental results show that dense electrode layer can be prepared solely by pressing the composite electrode with $\mathrm{Li}_{3} \mathrm{NbS}_{4}$ electrode and $75 \mathrm{Li}_{2} \mathrm{~S} \cdot 25 \mathrm{P}_{2} \mathrm{~S}_{5} \mathrm{SE}$ particles. The grain boundaries
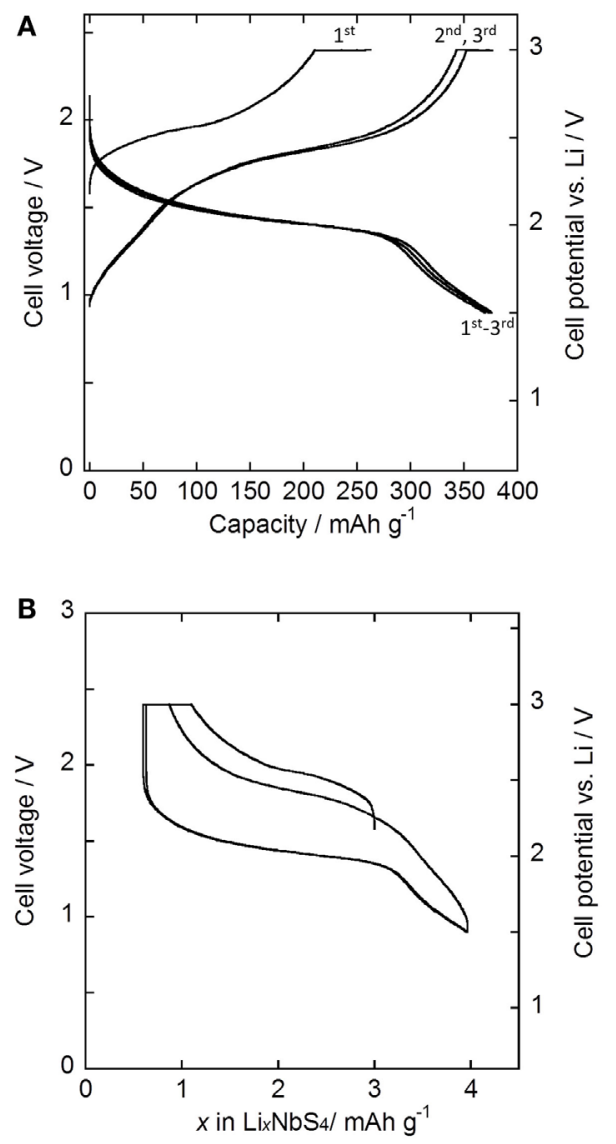

FIGURE 5 | (A) Charge-discharge curves of the all-solid-state $\mathrm{Li}-\mathrm{In} / \mathrm{Li}_{3} \mathrm{NbS}_{4}$ cells measured at $50^{\circ} \mathrm{C}$. (B) Charge-discharge curves with the number of lithium atoms per formula unit shown on the $x$-axis. The current density was $0.25 \mathrm{~mA} \mathrm{~cm}^{-2}$, and the cutoff voltage was $0.9-2.4 \mathrm{~V}$ vs. Li-In electrode. are hardly visible in the some interfaces between $\mathrm{Li}_{3} \mathrm{NbS}_{4}$ particles, indicating that this material sinters during pressing at room temperature. The $\mathrm{Li}_{3} \mathrm{NbS}_{4}$ particles are effectively deformed, make intimate contact, and create chemical bonds between the contacting particles. The cracking and fragmentation of electrode particles occur at the stress concentration point when typical lithium metal oxide electrodes, which are rather brittle materials, are used (Sakuda et al., 2016).

After charging and discharging, the electrode layer was still free of cracks (Figures 6A,B), despite the strong possibility of the electrode experiencing a large volume change during the charging and discharging cycle. The charge-discharge of $\mathrm{Li}_{3} \mathrm{NbS}_{4}$ involves large crystal structure changes, including amorphization. Therefore, it is difficult to determine the degree of volume change of the material by XRD measurements in charged and discharged electrodes. Thus, we estimated the volume change by measuring the molar volume of the mechanochemically prepared lithium niobium sulfides with the composition of $\mathrm{Li}_{x} \mathrm{NbS}_{4}(x=0,1,2$, and 3) (Sakuda et al., 2014d) by measuring the powder true density using a gas pycnometer. Table 1 summarizes the results of the powder true density measurements. These materials potentially include amorphous phase because of the preparation process. The powder true densities and molar volumes gradually changed as the lithium contents changed. The changes in the molar volume relative to $\mathrm{Li}_{3} \mathrm{NbS}_{4}$ range from $79 \%$ for $x=0$ to $106 \%$ for $x=4$. Thus, the molar volume of $\mathrm{Li}_{3} \mathrm{NbS}_{4}$ changes from ca. $82 \%(x=0.6)$ to $106 \%(x=4)$ during charging and discharging. In fact, the density of the electrode was largely changed during charging and discharging process (Figures 6A,B). Although an electrode that undergoes large volume changes usually exhibit fragmentation of the electrode particles, loss of interfacial contact between the electrode and electrolyte, and decreased packing density, these effects were not observed here. Instead, the electrode's density decreased by charging and increased by discharging relative to the as-prepared composite electrode layer (Figure 3). This result suggests that the room-temperature pressure sintering of the electrode particles occurred during discharging process, increasing the contact area of both electrode-electrolyte interface and electrode-electrode interface. The $\mathrm{Nb}-\mathrm{S}$ bond in the $\mathrm{Li}_{x} \mathrm{NbS}_{4}$ structure has a relatively covalent bond character and is relatively strong. The $\mathrm{Li}-\mathrm{S}$ bond in the $\mathrm{Li}_{x} \mathrm{NbS}_{4}$ structure has an intermediate bond character between ionic and covalent. The bond-dissociation energy of the $\mathrm{Li}-\mathrm{S}$ bond in $\mathrm{Li}_{3} \mathrm{NbS}_{4}$ is relatively small compared to that of a typical ionic bond, such as $\mathrm{Li}-\mathrm{F}$, and a typical covalent bond, such as $\mathrm{Si}-\mathrm{O}$. This intermediate bond character and relatively small bond energy make these particles

TABLE 1 | Powder true density, molar mass, molar volume, mean atomic volume, and change in molar volume (vs. $\mathrm{Li}_{3} \mathrm{NbS}_{4}$ ) of lithium niobium sulfides $\left(\mathrm{Li}_{x} \mathrm{NbS}_{4}\right)$ prepared by MM.

\begin{tabular}{|c|c|c|c|c|c|c|c|}
\hline$x$ in $\mathrm{Li}_{x} \mathrm{NbS}_{4}$ & Composition & $\begin{array}{l}\text { Observed } \\
\text { crystalline phase }\end{array}$ & $\begin{array}{c}\text { Powder true } \\
\text { density }\left(\mathrm{g} \mathrm{cm}^{-3}\right)\end{array}$ & $\begin{array}{l}\text { Molar mass } \\
\qquad\left(\mathrm{g} \mathrm{mol}^{-1}\right)\end{array}$ & $\begin{array}{l}\text { Molar volume } \\
\left(\mathrm{cm}^{3} \mathrm{~mol}^{-1}\right)\end{array}$ & $\begin{array}{l}\text { Mean atomic volume } \\
\qquad\left(\mathrm{cm}^{3} \mathrm{~mol}^{-1}\right)\end{array}$ & $\begin{array}{l}\text { Change in molar } \\
\text { volume (\%) }\end{array}$ \\
\hline 0 & $\mathrm{NbS}_{4}$ & Amorphous & 3.38 & 221.17 & 65.5 & 13.1 & 79.0 \\
\hline 1 & $\mathrm{LiNbS}_{4}$ & Amorphous & 3.24 & 228.11 & 70.4 & 11.7 & 84.9 \\
\hline 2 & $\mathrm{Li}_{2} \mathrm{NbS}_{4}$ & Rock salt & 3.12 & 235.05 & 75.3 & 10.8 & 90.8 \\
\hline 3 & $\mathrm{Li}_{3} \mathrm{NbS}_{4}$ & Rock salt & 2.92 & 241.99 & 82.9 & 10.4 & 100.0 \\
\hline 4 & $\mathrm{Li}_{4} \mathrm{NbS}_{4}$ & Antifluorite & 2.82 & 248.93 & 88.1 & 9.8 & 106.3 \\
\hline
\end{tabular}



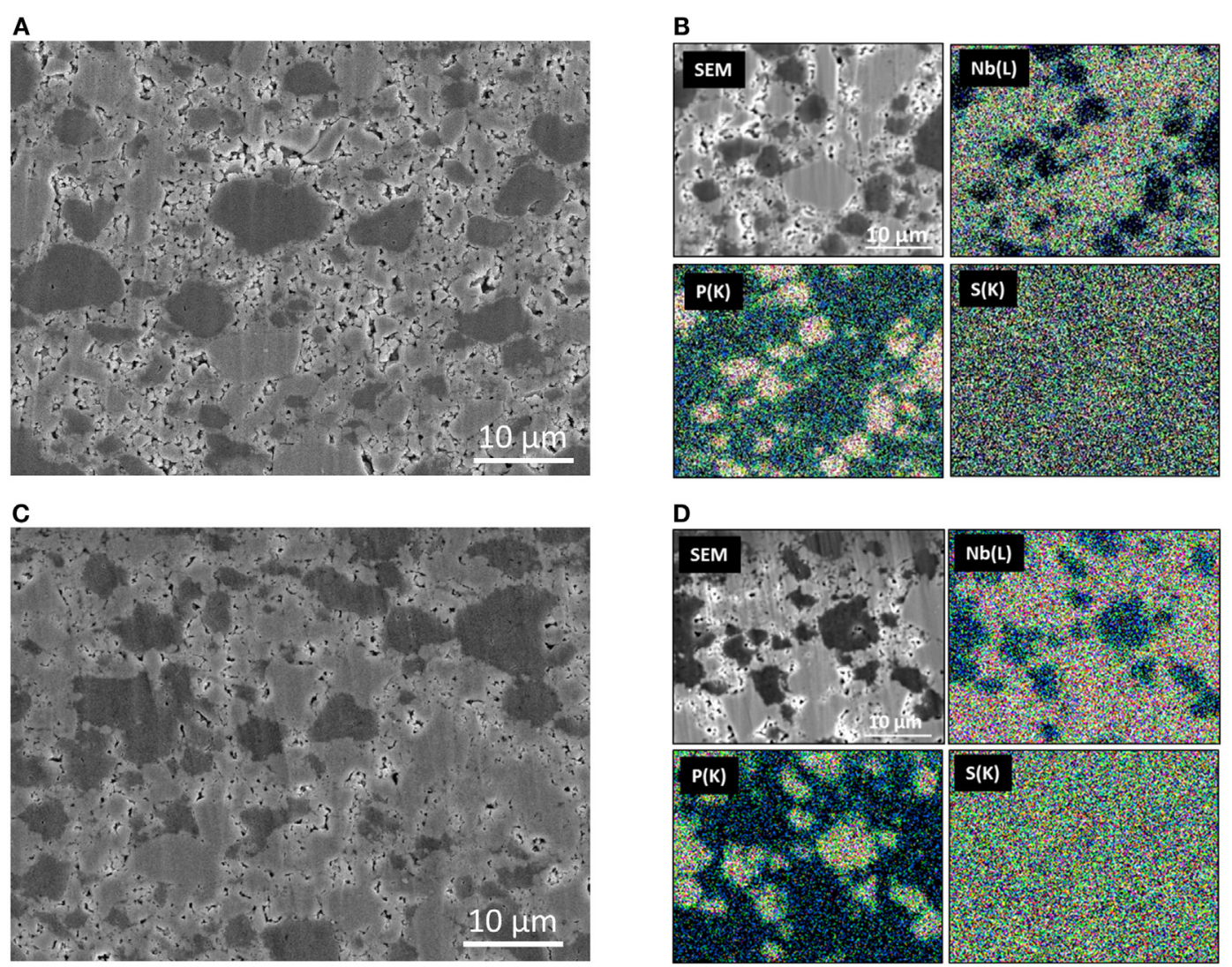

FIGURE 6 | Cross-sectional SEM images of the composite electrode of the all-solid-state cell after the first charging (A) and discharging (B). The EDX mappings for $\mathrm{Nb}-\mathrm{L}, \mathrm{P}-\mathrm{K}$, and $\mathrm{S}-\mathrm{K}$ of the cross-sections of the composite electrode after first charging (C) and discharging (D) are also shown.
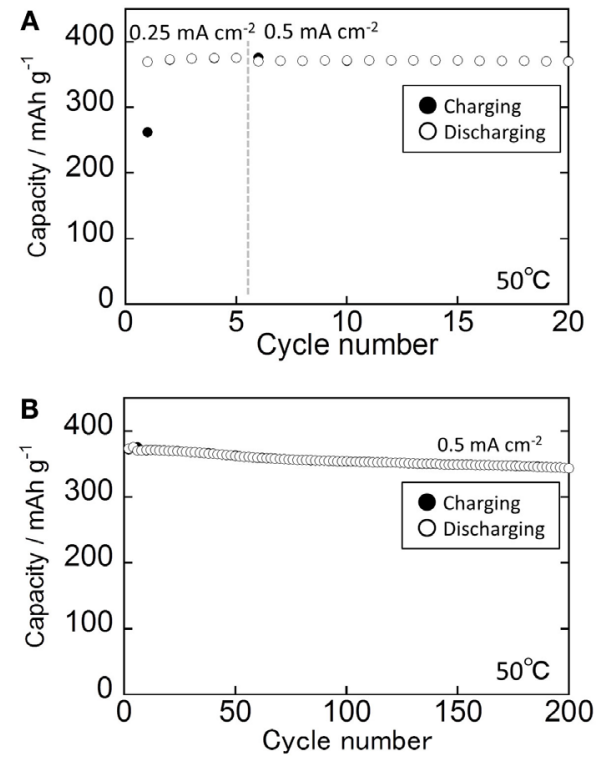

FIGURE 7 | Cycle performance of the all-solid-state $\mathrm{Li}-\mathrm{In} / \mathrm{Li}_{3} \mathrm{NbS}_{4}$ cell. (A) 1st to 20th cycle and (B) 1st to 200th cycles. amenable to room-temperature pressure sintering by quasiplastic deformation. Quasi-plastic deformation involves the breaking and reformation of chemical bonds, such as the Li-S bond. Furthermore, niobium's coordination structure is flexible in sulfide materials. Thus, the stress magnification factor of $\mathrm{Li}_{x} \mathrm{NbS}_{4}$ should be small, and the material should exhibit quasi-plastic deformation. The crystalline size of the $\mathrm{Li}_{3} \mathrm{NbS}_{4}$ in this study was very small; the crystalline diameter estimated based on the XRD pattern was $<10 \mathrm{~nm}$. The $\mathrm{Li}_{3} \mathrm{NbS}_{4}$ crystal domains are believed to be connected by an amorphous $\mathrm{Li}-\mathrm{Nb}-\mathrm{S}$ matrix. This structure is favorable for quasi-plastic deformation because amorphous phases usually have larger free volumes and smaller cohesive energies than crystal phases. Clearly, the application of some degree of pressure to the all-solid-state cells during operation is important for these cells' high performance. Under the applied pressure, the interfacial contact between the $\mathrm{Li}_{3} \mathrm{NbS}_{4}$ electrode and SE can be maintained despite relatively large volume changes.

The high cyclability of the all-solid-state batteries as shown in Figure 7 is attributable to the unique mechanical properties of the $\mathrm{Li}_{3} \mathrm{NbS}_{4}$ particles, which are believed to deform effectively without fragmentation during charging and discharging. The composite electrode layer rather becomes dense during discharging process, although the electrode becomes less dense during 
charging. This densification is also likely related to the small capacity increase during the initial several cycles.

In this study, we presented a new, qualitative perspective concerning the usefulness of deformable electrode materials in all-solid-state batteries. The effective electrode-electrode intimate contacts can be maintained even if the electrode shows volume changes during charging and discharging by using the deformable soft electrode materials. The transition metal sulfides with sulfur-rich composition are model materials as the soft electrode materials with high capacity. In addition to the deformability of electrode materials, many other factors, such as elastic modulus and morphology of the electrode particles, and the pore volume of the composite electrode, also affect battery performance. Therefore, additional quantitative studies are

\section{REFERENCES}

Armand, M., and Tarascon, J.-M. (2008). Building better batteries. Nature 451, 652-657. doi:10.1038/451652a

Bruce, P. G., Freunberger, S. A., Hardwick, L. J., and Tarascon, J.-M. (2012). Li- $\mathrm{O}_{2}$ and Li-S batteries with high energy storage. Nat. Mater. 11, 19-29. doi:10.1038/ nmat3191

Dunn, B., Kamath, H., and Tarascon, J.-M. (2011). Electrical energy storage for the grid: a battery of choices. Science 334, 928-935. doi:10.1126/science.1212741

Etacheri, V., Marom, R., Elazari, R., Salitra, G., and Aurbach, D. (2011). Challenges in the development of advanced Li-ion batteries: a review. Energy Environ. Sci. 4, 3243-3262. doi:10.1039/C1EE01598B

Hayashi, A., Hama, S., Morimoto, H., Tatsumisago, M., and Minami, T. (2001). Preparation of $\mathrm{Li}_{2} \mathrm{~S}-\mathrm{P}_{2} \mathrm{~S}_{5}$ amorphous solid electrolytes by mechanical milling. J. Am. Ceram. Soc. 84, 477-479. doi:10.1111/j.1151-2916.2001.tb00685.x

Hayashi, A., Matsuyama, T., Sakuda, A., and Tatsumisago, M. (2012a). Amorphous titanium sulfide electrode for all-solid-state rechargeable lithium batteries with high capacity. Chem. Lett. 41, 886-889. doi:10.1246/cl.2012.886

Hayashi, A., Noi, K., Sakuda, A., and Tatsumisago, M. (2012b). Superionic glassceramic electrolytes for room-temperature rechargeable sodium batteries. Nat. Commun. 3, 856-860. doi:10.1038/ncomms 1843

Ji, X., Lee, K. T., and Nazar, L. F. (2009). A highly ordered nanostructured carbon-sulphur cathode for lithium-sulphur batteries. Nat. Mater. 8, 500-506. doi:10.1038/NMAT2460

Kamaya, N., Homma, K., Yamakawa, Y., Hirayama, M., Kanno, R. M., Yonemura, R., et al. (2011). A lithium superionic conductor. Nat. Mater. 10, 682-686. doi:10.1038/NMAT3066

Matsuyama, T., Sakuda, A., Hayashi, A., Togawa, Y., Mori, S., and Tatsumisago, M. (2012). Preparation of amorphous $\mathrm{TiS}_{x}$ thin film electrodes by the PLD method and their application to all-solid-state lithium secondary batteries. J. Mater. Sci. 47, 6601-6606. doi:10.1007/s10853-012-6594-9

Minami, T., Hayashi, A., and Tatsumisago, M. (2006). Recent progress of glass and glass-ceramics as solid electrolytes for lithium secondary batteries. Solid State Ionics. 177, 2715-2720. doi:10.1016/j.ssi.2006.07.017

Sakuda, A., Hayashi, A., and Tatsumisago, M. (2013a). Sulfide solid electrolyte with favorable mechanical property for all-solid-state lithium battery. Sci. Rep. 3, 2261. doi:10.1038/srep02261

Sakuda, A., Taguchi, N., Takeuchi, T., Kobayashi, H., Sakaebe, H., Tatsumi, K., et al. (2013b). Amorphous $\mathrm{TiS}_{4}$ positive electrode for lithium-sulfur required to better understand the requirements to achieve "ideal" all-solid-state batteries.

\section{AUTHOR CONTRIBUTIONS}

AS wrote the manuscript and TT, MS, HS, and HK revised the manuscript. AS, TT, and HK designed the work. AS conducted the experiments and AS, TT, MS, HS, and HK characterized the materials.

\section{FUNDING}

This work was partially supported by JSPS KAKENHI (Grant Number 15K17920).

secondary batteries. Electrochem. commun. 31, 71-75. doi:10.1016/j. elecom.2013.03.004

Sakuda, A., Taguchi, N., Takeuchi, T., Kobayashi, H., Sakaebe, H., Tatsumi, K., et al. (2014a). Composite positive electrode based on amorphous titanium polysulfide for application in all-solid-state lithium secondary batteries. Solid State Ionics. 31, 143-146. doi:10.1016/j.ssi.2013.09.044

Sakuda, A., Taguchi, N., Takeuchi, T., Kobayashi, H., Sakaebe, H., Tatsumi, K., et al. (2014b). Amorphous niobium sulfides as novel positive-electrode materials. ECS Electrochem. Lett. 3, A79-A81. doi:10.1149/2.0091407eel

Sakuda, A., Takeuchi, T., Okamura, K., Kobayashi, H., Sakaebe, H., Tatsumi, K., et al. (2014c). Rock-salt-type lithium metal sulphides as novel positive-electrode materials. Sci. Rep. 4, 4883. doi:10.1038/srep04883

Sakuda, A., Takeuchi, T., Kobayashi, H., Sakaebe, H., Tatsumi, K., and Ogumi, Z. (2014d). Preparation of novel electrode materials based on lithium niobium sulfides. Electrochemistry 82, 880-883. doi:10.5796/electrochemistry.82.880

Sakuda, A., Takeuchi, T., and Kobayashi, H. (2016). Electrode morphology in all-solid-state lithium secondary batteries consisting of $\mathrm{LiNi}_{1 / 3} \mathrm{Co}_{1 / 3} \mathrm{Mn}_{1 / 3} \mathrm{O}_{2}$ and $\mathrm{Li}_{2} \mathrm{~S}-\mathrm{P}_{2} \mathrm{~S}_{5}$ solid electrolytes. Solid State Ionics. 285, 112-117. doi:10.1016/j. ssi.2015.09.010

Schuster, J., He, G., Mandlmeier, B., Yim, T., Lee, K. T., Bein, T., et al. (2012). Spherical ordered mesoporous carbon nanoparticles with high porosity for lithium-sulfur batteries. Angew. Chem. Int. Ed. 51, 3591. doi:10.1002/ anie. 201107817

Takada, K., Aotani, N., Iwamoto, K., and Kondo, S. (1996). Solid state lithium battery with oxysulfide glass. Solid State Ionics. 86-88, 877-882. doi:10.1016/0167-2738(96)00199-3

Yamin, H., and Peled, E. (1983). Electrochemistry of a non-aqueous lithium sulfur cell. J. Power Sources 9, 281-287. doi:10.1016/0378-7753(83)87029-3

Conflict of Interest Statement: The authors declare that the research was conducted in the absence of any commercial or financial relationships that could be construed as a potential conflict of interest.

Copyright (c) 2016 Sakuda, Takeuchi, Shikano, Sakaebe and Kobayashi. This is an open-access article distributed under the terms of the Creative Commons Attribution License (CC BY). The use, distribution or reproduction in other forums is permitted, provided the original author(s) or licensor are credited and that the original publication in this journal is cited, in accordance with accepted academic practice. No use, distribution or reproduction is permitted which does not comply with these terms. 